\title{
Karakteristik dan Keterampilan Pramusaji di Era Revolusi Industri 4.0 pada Hotel The Oberoi Beach Resort Bali
}

\author{
Gede Elga Krisna Gita, Yudha M. Mahardika , Ni Made Ary \\ Widiastini \\ Undiksha
}

\begin{abstract}
Abstrak
Penelitian ini bertujuan untuk mengetahui karakteristik dan keterampilan pramusaji di era revolusi industri 4.0 di The Oberoi Beach Resort Bali. Penelitian ini merupakan penelitian deskriptif kualitatif dengan menggunakan observasi dan wawancara sebagai metode pengumpulan datanya. Subjek penelitian diambil dari Hotelier di bidang pemerintahan dan HRD. Selain keterampilan bahasa asing, komunikasi yang baik, terdapat tambahan keterampilan dan ciri khas era revolusi 4.0 yang terdapat pada penelitian ini terdapat 4 ciri (literasi teknologi, mengikuti perkembangan bidang pemerintahan, mampu bekerja secara efisien dan efektif serta menguasai teknologi dan sistem) dan 4 keterampilan (mengikuti perkembangan zaman, dapat menggunakan alat-alat baru yang terkait dengan pekerjaan operasional, mengikuti tren layanan terkini dan memahami sistem dan komputer) pelayan di era revolusi industri 4.0. Kedepannya diharapkan akan ada kajian-kajian yang membahas topik yang sama agar lebih banyak menelaah sumber dan referensi terkait karakteristik dan keterampilan pramusaji di era 4.0, sehingga mendapatkan hasil yang lebih baik dan lebih lengkap.
\end{abstract}

Kata kunci: Pelayanan, Pramusaji, Revolusi Industri 4.0, Keterampilan abad-21

This study aimed to finding the characteristics and skills of waiters in the era of the industrial revolution 4.0 on The Oberoi Beach Resort Bali. This research was a qualitative descriptive study, using observation and interviews as a method of collecting data. Subject of the study were drawn from Hotelier in the field of governance and HRD. In addition to foreign language skills, good communication, there are additional skills and characteristics in the revolutionary era 4.0 found in this study are 4 characteristics (technological literacy, following developments in the field of governance, being able to work efficiently and effectively and mastering technology and systems) and 4 skills (following the times, can use new tools related to operational work, follow the latest service trends and understand the system and computers) waiters in the era of the industrial revolution 4.0. In the future, it was expected that there will be studies that discuss the same topic in order to study more sources and references related to the characteristics and skills of waiters in the 4.0 era, so that they get better and more complete results.

Keywords: Service, Waiters, Industrial Revolution 4.0, and 21st Century Skills

\section{Pendahululuan}

Dunia pariwisata sangat kental akan sebuah pelayanan terhadap pengunjung. Pelayanan menjadi kunci suksesnya sebuah hotel ataupun restoran. 'Tamu adalah Raja' merupakan salah satu jargon yang sering terdengar di bidang pelayanan. Jargon tersebut bermakna bahwasanya seorang pramusaji hotel atau restaurant harus mampu melayani tamu dengan baik, seolah olah tamu tersebut adalah raja. Pramusaji akan menjadi baris 
JMPP, Vol 3 No 1, April 2020

p-ISSN: 2654-9719

terdepan dalam menjamu dan melayani tamu di restoran sehingga dapat berkesan dan tamu yang dilayani akan merasa senang dan puas (Eka, 2015). Sebab, pelayanan yang baik tentunya mampu meningkatkan penghasilan. Pelayanan yang baik juga akan menambah kredibelitas hotel ataupun restaurant. dari berbagai referensi tersebut,dapat terlihat bahwa pelayanan dapat mempengaruhi bermacam variable dalam bisnis perhotelan.

Kualitas pelayanan yang baik bisa didapatkan dari tenaga kerja yang terampil. Sebagai frontliner diperlukan tenaga kerja yang tepat dan berkualitas pada bagian F\&B Service demi terwujudnya pelayanan prima kepada tamu (Adilla, 2017). Normasari (2013), dalam penelitiannya menyebutkan bahwa kualitas pelayanan secara langsung memiliki pengaruh yang signifikan terhadap kepuasan pelanggan. la menjelaskan bahwa selaian berpengaruh terhadap kepuasan pelanggan, kualitas pelayanan juga mempengaruhi citra perusahaan dan juga loyalitas pelanggan. Maka simpulan dari referensi tersebut adalah kualitas pelayanan secara langsung memberikan dampak positif yang signifikan terhadap kepuasan pelanggan.

Tenaga kerja terampil di bidang perhotelan wajib memiliki berbagai ketrampilan. Prilaku yang baik, pengetahuan, dan keterampilan yang memadai harus dimiliki seorang karyawan hotel untuk berkiprah di dunia perhotelan (Dieni, 2019). Lebih lanjut, si Asmawati (2019) menambahkan tenaga kerja wajib memiliki ketrampilan berupa kompetensi teknis, kompetensi sosial, kompetensi personal dan kompetensi profesional/ketrampilan metodologis dalam menghadapi abad 21. Keterampilan baru di bidang teknologi informasi maupun analisis data merupakan suatu hal wajib dimiliki tenaga kerja. Dapat disimpulkan bahwa tenaga terampil di bidang perhotelan membutuhkan ketrampilan teknis, sosial, personal, professional, teknologi informasi dan analisis data disamping memiliki attitude serta knowledge.

Walaupun berbagai referensi mengenai berbagai jenis ketrampilan sudah banyak ditemukan, belum banyak penelitian yang dilakukan untuk menggali ketrampilan dan karakteristik ideal pramusaji di era 4.0. Pengetahuan, respon yang cepat, keterampilan dan attitude menjadi kebutuhan yang harus dimiliki seorang pramusaji. Menurut Zeithaml, Berry dan Parasuraman (dalam Zulian Yamit, 2005:10, dalam Zulkifli, 2016), mengidentifikasi lima dimensi karakteristik yang digunakan oleh pramusaji dalam mengevaluasi kualitas pelayanan diantaranya: kehandalan, daya tanggap, jaminan, empathy, dan tangibles (bukti langsung). Terdapat beberapa penelitian yang menganalisa mengenai karakteristik dan ketrampilan tenaga kerja di bidang pariwisata dan perhotelan. Si Wachidyah (2017) meneliti mengenai karakteristik FO, sedang si Ramadani (2016) menggali mengenai ketrampilan di bagian HK, dan si Brigitha (2018) mengkhususkan pada bagian tour guide. Akan tetapi, karakteristik dan ketrampilan pramusaji di era 4.0 masih belum terekam 
JMPP, Vol 3 No 1, April 2020

p-ISSN: 2654-9719

dengan baik dalam sebuah penelitian. oleh karenanya, penelitian ini dirasa penting untuk dilakukan, guna mengisi kesenjangan dalam penelitian mengenai karakteristik dan ketrampilan pramusaji di era 4.0

Tujuan penelitian ini adalah untuk mengetahui karakteristik dan keterampilan yang bagaimana seharusnya dimiliki oleh seorang pramusaji di era industri 4.0 hotel The Oberoi Resort Bali. Dengan mengambil informasi dari bagian HRD, Manajer, Supervisor di bagian tata hidang atau pelayanan. Diharapkan mampu memberikan argument-argument serta informasi yang baik, guna mendukung keberhasilan penelitian ini.

\section{KajianPustaka}

Kualitas pelayanan yang baik bisa didapatkan dari tenaga kerja yang terampil. Sebagai frontliner diperlukan tenaga kerja yang tepat dan berkualitas pada bagian F\&B Service demi terwujudnya pelayanan prima kepada tamu (Adilla, 2017). Normasari (2013), dalam penelitiannya menyebutkan bahwa kualitas pelayanan secara langsung memiliki pengaruh yang signifikan terhadap kepuasan pelanggan. la menjelaskan bahwa selaian berpengaruh terhadap kepuasan pelanggan, kualitas pelayanan juga mempengaruhi citra perusahaan dan juga loyalitas pelanggan. Maka simpulan dari referensi tersebut adalah kualitas pelayanan secara langsung memberikan dampak positif yang signifikan terhadap kepuasan pelanggan.

Tenaga kerja terampil di bidang perhotelan wajib memiliki berbagai ketrampilan. Prilaku yang baik, pengetahuan, dan keterampilan yang memadai harus dimiliki seorang karyawan hotel untuk berkiprah di dunia perhotelan (Dieni, 2019). Lebih lanjut, si Asmawati (2019) menambahkan tenaga kerja wajib memiliki ketrampilan berupa kompetensi teknis, kompetensi sosial, kompetensi personal dan kompetensi profesional/ketrampilan metodologis dalam menghadapi abad 21. Keterampilan baru di bidang teknologi informasi maupun analisis data merupakan suatu hal wajib dimiliki tenaga kerja. Dapat disimpulkan bahwa tenaga terampil di bidang perhotelan membutuhkan ketrampilan teknis, sosial, personal, professional, teknologi informasi dan analisis data disamping memiliki attitude serta knowledge.

Walaupun berbagai referensi mengenai berbagai jenis ketrampilan sudah banyak ditemukan, belum banyak penelitian yang dilakukan untuk menggali ketrampilan dan karakteristik ideal pramusaji di era 4.0. Pengetahuan, respon yang cepat, keterampilan dan attitude menjadi kebutuhan yang harus dimiliki seorang pramusaji. Menurut Zeithaml, Berry dan Parasuraman (dalam Zulian Yamit, 2005:10, dalam Zulkifli, 2016), mengidentifikasi lima dimensi karakteristik yang digunakan oleh pramusaji dalam mengevaluasi kualitas pelayanan diantaranya: kehandalan, daya tanggap, jaminan, empathy, dan tangibles (bukti langsung). Terdapat beberapa penelitian yang menganalisa mengenai karakteristik dan 
JMPP, Vol 3 No 1, April 2020

p-ISSN: 2654-9719

ketrampilan tenaga kerja di bidang pariwisata dan perhotelan. Si Wachidyah (2017) meneliti mengenai karakteristik FO, sedang si Ramadani (2016) menggali mengenai ketrampilan di bagian HK, dan si Brigitha (2018) mengkhususkan pada bagian tour guide. Akan tetapi, karakteristik dan ketrampilan pramusaji di era 4.0 masih belum terekam dengan baik dalam sebuah penelitian. oleh karenanya, penelitian ini dirasa penting untuk dilakukan, guna mengisi kesenjangan dalam penelitian mengenai karakteristik dan ketrampilan pramusaji di era 4.0.

\section{Metodelogi Penelitian}

Design penelitian yang digunakan adalah deskriptif kualitatif. Menurut Anselm Strauss \& Juliet Corbin (dalam buku "Dasar-dasar Penelitian Kualitatif" dalam Suardana dan Nurhayati, 2019), dijelaskan bahwa penelitian kualitatif dimaksudkan sebagai jenis penelitian yang temuan-temuan yang tidak diperoleh melalui prosedur statistik atau bentuk hitungan lainnya.

Penelitian ini dimulai dengan observasi pada subjek penelitian yaitu Manager department F\&B Service, supervisor di masing-masing section F\&B Service, beberapa staf dari F\&B Service serta di bagian HRD department. Rumusan masalah nantinya akan dijawab dengan cara pengumpulan data dengan metode wawancara online dan metode dokumentasi. Setelah data dikumpulkan dengan lengkap, data akan diolah dengan teknik deskriptif kualitatif guna memaparkan serta memberikan penjelasan mengenai data-data yang didapat pada saat wawancara online dan nantinya akan ditarik kesimpulan sesuai dengan hasil penelitian.

\section{Hasil Penelitian dan Pembahasan}

\subsection{Karakteristik Pramusaji Di Era Revolusi Industri 4.0}

Berdasarkan pemaparan narasumber pada penelitian ini, terdapat beberapa karakteristik seorang pramusaji saat ini dan di era revolusi industri 4.0. Diantaranya; 1) memiliki attitude yang baik, 2) berpenampilan yang rapi dan sesuai standarisasi yang telah ditentukan perusahaan, 3) memiliki track record pengalaman kerja yang bagus, 4) first impression yang bagus, 5) memiliki pengetahuan dibidang tata hidang dan 6) memiliki etos kerja yang tinggi. Selain itu terdapat juga karakteristik tambahan sebagai seorang pramusaji di era revolusi industri 4.0 sebagai berikut; 1) melek teknologi atau tidak gagap teknologi, 2) mengikuti perkembangan dan perubahan terkait dengan tata hidang, 3) menguasai teknologi maaupun system entah itu penggunaan tablet, komputer dll, dan 4) mampu bekerja secara Effisien (multitasking dalam bekerja) dan effektif (penggunaan bahan).

Hasil penelitian tersebut sejalan dengan apa yang di jelaskan White \& Beckley Jurnal Manajemen Perhotelan dan Pariwisata | 32 
JMPP, Vol 3 No 1, April 2020

p-ISSN: 2654-9719

dalam Sugiato, (2002: 10), bahwasanya terdapat beberapa karakteristik pramusaji diantaranya; 1) neatness (berpenampilan rapi), 2) berbicara secara bijaksana dan melakukan segala sesuatu secara benar, 3) menggunakan akal sehat dalam memahami orang lain, 4) respect (menghormati dan menghargai orang lain). Di sisi lain, dari pengalaman penulis saat melaksanakan PKL (Praktek Kerja Lapangan) bahwa karakteristik pramusaji sesuai dengan apa yang di sampaikan oleh beberapa narasumber seperti halnya berpenampilan rapi sesuai dengan SOP, attitude yang baik, respect terhadap pekerjaan maupun kepada tamu dsb.

\subsection{Keterampilan Pramusaji Di Era Revolusi Industri 4.0}

Dari hasil pemaparan oleh pelaku wisata di bidang F\&B Service dan HRD dapat dilihat beberapa ketereampilan yang dimiliki seorang pramusaji, baik saat ini maupun di era revolusi industri 4.0. Keterampilan pramusaji yang saat ini seperti; 1) Komunikasi dalam bahasa asing, 2) memiliki basic skill dalam menyajikan makanan dan minuman, 3) memiliki pengetahuan product knowledge, 4) bisa melakukan up-selling pada saat menawarkan produk. Dan dari pemaparan dari narasumber juga terdapat keterampilan pramusaji di era rovolusi industri 4.0 seperti; 1) mengikuti perkembangan maupun perubahan zaman dalam artian melek teknologi, 2) bisa menggunakan alat-alat baru dalam kebutuhan opersional seperti tablet (taking order), komputer, mesin kasier dan peralatan lainnya, 3) mengikuti tren pelayanan yang terbaru, 4) mengerti sistem (kasir, laporan hasil penjualan), computer ( Word, Exel, Power Point ( 3 basic minim yang sering digunakan dalam dunia kerja).

Dari hasil penelitian di atas sejalan dengan teori yang di sampaikan oleh Wagner (2010) dan Change Leadership Group dari Universitas Harvard dalam Zubaidah (2016:2), bahwasanya berkomunikasi secara baik, ketangkasan dalam beradaptasi, mampu menganalis dan mengakses informasi serta inisiatif dan berjiwa interpreneur merupakan keterampilan dalam menghadapi dunia kerja di abad 21. Selain itu keterampilan, pengetahuan dan pengalaman kerja menjadi beberapa karakteristik yang harus dimiliki pramusaji seperti teori yang dikemukakan oleh Winardi (2002) dalam Eka (2015).

\section{Penutup}

Berdasarkan pembahasan yang telah dipaparkan di atas, adapun simpulan dari penelitian mengenai karakteristik dan keterampilan pramusaji di era revolusi industri 4.0 yang dilaksankan di hotel The Oberoi Beach Resort Bali bahwa terdapat 4 karakteristik pramusaji yaitu; 1) melek teknologi, 2) mengikuti perkembangan terkait dengan tata hidang, 3) menguasai teknologi maupun system, 4) mampu bekerja secara efisien dan efektif, dan juga 4 keterampilan pramusaji; 1) bisa mengikuti perkembangan zaman, 2) bisa 
menggunakan alat-alat baru terkait operasional kerja, 3) mengikuti tren pelayanan terbaru, dan 4) Mengerti sistem (kasir, laporan hasil penjualan), dan komputer.

Penelitian ini belum bisa digeneralisasikan karenamasih banyak keterbatasan mengingat lingkup serta jumlah lokasi penelitiannya masih lingkup daerah Bali. Kedepannya diharapkan terdapat peneletian yang membahas topik sama agar mengkaji lebih banyak sumber maupun referensi yang terkait dengan karakteristik dan keterampilan pramusaji di era 4.0, sehingga mendapat hasil yang lebih baik dan lengkap.

\section{Daftar Pustaka}

Adilla, Fathia. 2017. Kualitas Pelayanan Waiter Dan Waitress Tirta Ayu Restoran Pada Hotel Aryaduta Pekanbaru. JOM FISIP Vol. 4, No. 1. Pekanbaru, Riau.

Asmawati. 2019. Dampak Industri 4.0 Pada Pasar Kerja Dan Pendidikan Tinggi. Jurnal Abulyatama. Aceh Besar.

Brigitha, Breda Tumbel dkk. 2018. The Impact Of Knowledge And Skills Of Tour Guide On Tourist's Satisfaction In Bunaken. Jurnal EMBA Vol. 6, No. 2. Manado.

Eka, Yuki Lusiana. 2015. Pengaruh Metode Pelatihan Kerja Terhadap Peningkatan Keterampilan Pramusaji Food \& Beverage Service Swissbelhotel Harbour Bay Batam. Jom FISIP Vol. 2, No.2. Pekanbaru.

Erlike, Fitria. 2016. Pentingnya Peranan Skill Dan Menu Knowledge Waiter/Waiters Terhadap Kepuasan Pelanggan Di Food And Beverage Service Departement (Studi Kasus Di Casa Del Rio Melaka Malaysia). Malang.

Dieni, Novita Al Ihyak. 2019. Peningkatan Ketrampilan Bebahasa Inggris Bagi Karyawan Hotel Fovere Bandara Semarang (The Improvement of English Language Skill for Fovere Hotel Semarang Airport Staff). Journal of Law, English, and Economics Vol. 1, No. 1. Semarang.

Ibrahim, Mariaty. 2018. Kualitas Pelayanan Waiter Di Hotel Alpha Pekanbaru. Jom FISIP Vol. 5, No. 1. Riau.

Kusnandar, Adit. 2019. Revolusi Industri 1.0 Hingga 4.0. Bandar Lampung.

Majidah, dkk. 2019. Keterampilan Literasi Informasi Mahasiswa Dalam Menghadapi Revolusi Industri 4.0. Jurnal Perpustakaan, Arsip dan Dokumen Vol. 11, No. 1. Padang.

Normasari, Selvy dkk. 2013. Pengaruh Kualitas Pelayanan Terhadap Kepuasan Pelanggan, Citra Perusahaan Dan Loyalitas Pelanggan. Jurnal Administrasi Bisnis (JAB) | Vol. 6 No. 2. Malang.

Prasetyo, Hoedi dan Wahyudi Sutopo. 2018. Industri 4.0: Telaah Klasifikasi Aspek Dan Arah Perkembangan Riset. Jurnal Teknik Industri Vol. 13, No. 1. Surakarta.

Ramadani, Elni. 2016. Kinerja Karyawan Housekeeping Di Hotel Unigraha Pangkalan 
Kerinci. Jom FISIP Vol. 3, No. 2. Riau.

Suardana, Neneng Nurhayati. 2019. Kinerja Waiter/Waitress Dalam Upaya Meningkatkan Kualitas Pelayanan (Studi Kasus Di Hotel Sahid Raya Yogyakarta). Jurnal Nusantara (Jurnal Ilmiah Pariwisata dan Perhotelan) Vol. 2, No.2. Yogyakarta.

Sugiarto, Endar 2002 Psikologi Pelayanan Dalam IndustriJasa PT.Gramedia Pustaka Utama. Jakarta.

Susepti, Amalia dkk. 2017. Pengaruh Kualitas Pelayanan Terhadap Kepuasan Dan Loyalitas Tamu Hotel (Studi Tentang Persepsi Tamu Hotel Mahkota Plengkung Kabupaten Banyuwangi). Jurnal Administrasi Bisnis (JAB) Vol. 50 No. 5. Banyuwangi.

Wachidyah, Wiwin. 2017. Front Office Department Dan Peranannya Dalam Layanan Tamu Hotel. JurnalBisnis \&Teknologi Politeknik NSC Surabaya Vol. 4, No. 1. Surabaya.

Zubaidah, Siti. 2016. Keterampilan Abad Ke-21: Keterampilan Yang Diajarkan Melalui Pembelajaran. Malang. Zubaidah, Siti. 2018. Mengenal 4c: Learning And Innovation Skills Untuk Menghadapi Era Revolusi Industri 4.0. Malang.

Zulkifli. 2016. Pengaruh Waiter Profesional Dalam Meningkatkan Kualitas Pelayanan Di Restoran Harris Café Harris Resort Waterfront Hotel Batam. Jom FISIP Vol. 3, No. 2. Batam. 